\title{
Totalitarismo y lenguaje: el campo de concentración como espacio multilingüe y la figura del intérprete concentracionario
}

\author{
Laura Miñano Mañero ${ }^{1}$ \\ Universitat de València \\ Departament de Teoria dels Llenguatges i Ciències de la Comunicació. Becaria FPU · Av. de Blasco Ibáñez, $32 \cdot 46010$. \\ València $\cdot$ Spain
}

\section{RESUMEN}

En este trabajo se examinan las relaciones entre el poder absoluto y el lenguaje. Los campos de concentración del régimen nacionalsocialista se entienden como el espacio donde se materializa la máxima expresión del totalitarismo. Al convertirse en sociedades forzadamente multilingües desde el inicio de la guerra, la lengua alemana puede convertirse, más que nunca, en un instrumento más de opresión al servicio del sistema: se deforma para convertirse prácticamente en un protolenguaje violento y rudimentario, y su conocimiento por parte de los reclusos se relaciona siempre con las perspectivas de supervivencia. Además, se desarrolla una lengua franca que incorpora rasgos de varios idiomas hablados por los deportados; sirve para la comunicación entre los prisioneros y pone de manifiesto las estructuras sociales del campo. En este contexto, surge inevitablemente la figura del intérprete concentracionario, el enlace comunicativo entre persecutores y perseguidos. El estudio de su comportamiento parece de especial interés para poder alcanzar conclusiones sobre la mediación interlingüística en espacios de máxima presión.

Comunicación, interpretación, totalitarismo, campos de concentración

\section{ABSTRACT}

This paper examines the relationships between absolute power and language. Nazi concentration camps embody the space where the maximum expression of totalitarianism was put into practice. By becoming forcedly multilingual societies from the onset of the war, the German language grew to be, more than ever, an instrument of oppression at the service of the system: deformed and distorted, it practically evolved into a violent and rudimentary protolanguage. Being able to acquire and use this new form of speech was directly related to the prisoners' prospects of survival. In addition, a lingua franca that incorporated features of several languages spoken by the deportees naturally emerged; it was used in the communication among inmates and revealed the social structures of the camp. In this intercultural space, concentrarionary interpreters arose as the communicative link between persecutors and persecuted. The study of their behavior seems especially interesting for researchers concerned about enlightening the mechanisms through which interlinguistic mediation develops in spaces of maximum pressure.

Communication, interpretation, totalitarianism, concentration camps

\section{Introducción}

Los campos de concentración del Tercer Reich constituyen un espacio de gran interés para la sociolingüística. El estallido de la guerra significa un punto de inflexión en la historia de los KZ (Konzentrationslager o campo de concentración) que, habiendo sido concebidos originalmente como lugares de represión para el establecimiento del régimen, pasarán a convertirse en el instrumento clave para la consolidación del poder totalitario del régimen. El inicio del conflicto armado implica también un cambio significativo en la fisiología 
social del Lager, cuya sociedad procederá a internacionalizarse progresivamente: tras la detención del enemigo interno del régimen - que comenzó centrándose en individuos políticamente peligrosos, para después extenderse a otros sectores de la sociedad alemana considerados indeseables y parasitarios, tales como vagabundos, borrachos, alborotadores o prostitutas - , al sistema de poder absoluto le corresponde subyugar al enemigo externo, debido a la naturaleza intrínseca del movimiento totalitario, que aspira inevitablemente a la dominación política global (Arendt, 2006, p. 531).

Los campos se extenderán por todos los territorios ocupados del Reich, y en ellos empezará a establecerse esa sociedad internacional - en cada uno de ellos pudiendo llegar a coexistir cuarenta nacionalidades diferentes (Aschenberg, 2016, p. 64) - abstraída del mundo exterior, masivamente abarrotada y condenada al empeoramiento continuo de sus condiciones de vida. En cada Lager, el sistema opresor se encargará de construir unas complejas estructuras sociales (Sofsky, 2016, p. 146) y de elaborar una categorización de presos que, siguiendo criterios racistas, estigmatizadores y demarcatorios (p. 183), servirán para conseguir la subordinación absoluta del hombre-masa. Igualmente, la autogestión de los campos por parte de los presos contribuirá a fomentar la desigualdad y las diferencias entre los internos. En este universo forzadamente multicultural y políglota, la lucha por la supervivencia se establecerá como norma; ahora bien, no parecería correcto considerar las sociedades concentracionarias como espacios amorales sino, más bien, como lugares en los que se manifiestan unas condiciones de sociabilidad y unos códigos éticos nuevos, diferentes de los del universo exterior (Todorov, 2010, p. 70). Siguiendo a Arendt, parece que los nazis utilizan los campos de concentración “como laboratorios especiales para realizar su experiencia de la dominación total” (2006, p. 535).

En este contexto, en las sociedades concentracionarias - caracterizadas por la aplicación directa del poder absoluto sobre individuos que, además, están forzados a convivir con nacionalidades y lenguas diversas - se construye un sistema intercultural cuyo análisis conjunto puede llevarnos a nuevas conclusiones sobre los mecanismos sociolingüísticos que se desarrollan en estos espacios tan particulares. Sin embargo, existen múltiples complicaciones metodológicas a la hora de intentar abordar un estudio de estas características. En primer lugar, es necesario advertir la imposibilidad de concebir una noción única de campo (Prenninger, 2016, p. 27), lo cual implicaría la creación de un constructo ficticio excesivamente genérico y que no correspondería a la realidad histórica; de hecho, nunca existió un solo tipo de campo a lo largo de la dominación nacionalsocialista. Un trabajo consistente necesariamente debe considerar la cronología y evolución de los campos de concentración, el contexto particular de cada Lager, la tipología a la que correspondían — que determinaba sus funciones y sus condiciones de vida - y las implicaciones psicológicas de estos factores para cada uno de los deportados. Así los define Prenninger (2016):

Concentration camps are rather characterized by a fluidity of conditions in relation to chronological, spatial, and typological aspects. Most survivors, in their accounts, accentuate the different experiences they had in different camps. The key question, however, which is raised in almost every account, is why and how they survived (p. 28).

A partir de esta cita podemos fácilmente plantearnos la segunda dificultad que entraña una investigación de esta naturaleza: ¿Qué tipo de fuentes documentales podemos emplear para estas aproximaciones? Heidi Aschenberg (2016, p. 65) enfatiza los problemas a los que nos enfrentamos para poder conseguir una reconstrucción lingüística auténtica de la comunicación en los campos. El hecho es que, además de la muy reducida documentación administrativa y oficial relativa al lenguaje del Lager, solamente podemos contar con las memorias de los supervivientes, cuya grave heterogeneidad señala también la autora. 
Del mismo modo, somos conscientes también de las limitaciones que conlleva el estudio de la literatura concentracionaria, y particularmente los acercamientos que, como en nuestro caso, se orienten a la exploración sociolingüística. Por una parte, nos interesa especialmente aquello que Gramling ha denominado "multilingual survival" (2012, p. 180): el canon historiográfico de la literatura del Holocausto se encuentra incompleto y favorece el testimonio de los autores plurilingües, cuya supervivencia en el campo, como demostraremos, era más viable - parece necesario referir en este punto algunas palabras de Levi, que llevan al extremo esta consideración sobre el carácter incompleto del corpus del que disponemos: "no somos nosotros, los supervivientes, los verdaderos testigos" sino que son "los hundidos, los testigos integrales, aquellos cuya declaración habría podido tener un significado general ... Nosotros hablamos por ellos, por delegación" (Levi, 1986, p. 72-73) - . Por otra parte, Gramling también advierte (2012, p. 181-182) cómo los textos de los supervivientes fueron lingüísticamente manipulados y forzados en su publicación en la posguerra y, para favorecer la comprensión de lectores ajenos al universo KZ, "concentracionary language was thus entrusted to the prewar national languages. [...] Testimony needed to be shepherded out of the translingual matrix of its production".

Por tanto, son muchas las restricciones y complicaciones que surgen para reconstruir fielmente el contexto comunicativo concentracionario. Ahora bien, siguiendo las ideas de Sánchez Zapatero (2010, p. 41), que pone de manifiesto cómo la escritura sirve para transmitir y materializar el recuerdo, y el hecho de que la memoria colectiva se sustenta también en interpretaciones personales de la historia, parece evidente que "en determinadas ocasiones, ser víctima, testigo y superviviente sea suficiente legitimación para alzar la voz y contar lo vivido" (p.43). Además, como sucede en el caso de la literatura concentracionaria, los textos del escritor-testigo pueden constituir la única fuente de información relativa a un acontecimiento relevante y ensombrecido y, por lo tanto, la única manera de interpretación, actuación y superación histórica. Sánchez Zapatero saca a relucir el imperativo moral que siente por ello el superviviente: "de ahí que reflexionar sobre lo vivido [...] se convierta en una obligación para con la sociedad en un compromiso con la verdad que se intenta ocultar" (p. 41).

Por tanto, en este trabajo, nos serviremos de los testimonios autobiográficos de supervivientes procedentes de diversas naciones europeas. Considerando las diferencias estructurales de cada campo y el contexto personal de cada autor, creemos posible tratar de establecer, a partir de aquello que comparten en esencia las vivencias de los deportados, una perspectiva sociolingüística centrada principalmente en los actos de interpretación que se dan por fuerza en estas sociedades multiculturales. Sin embargo, dado que la interpretación se caracteriza inevitablemente por una embodied and oral agency, en el sentido de que la presencia física necesaria del mediador le confiere poder, pero también le hace vulnerable ante los conflictos (Cronin, 2006, p. 81), parece necesario, para poder comprender la actuación concreta de los intérpretes, contextualizar antes la posición social y lingüística del universo $\mathrm{KZ}$.

Para ello, en primer lugar realizaremos una aproximación más detallada al concepto de poder absoluto y sus implicaciones psicológicas en aquellos individuos sobre los que se establece la dominación total. En segundo lugar, examinaremos algunas características básicas de los campos de concentración, que constituyen los espacios en los que el sistema totalitario se manifiesta en su máxima expresión. Nos interesaremos, sobre todo, en ver sobre qué principios y de qué manera se construyen las estructuras sociales de los campos. A continuación, analizaremos brevemente la situación lingüística que se desarrolla en el Lager, siguiendo la teoría de que el campo se organiza en torno a la confusión de lenguas y a unos principios lingüísticos represivos; se trata de un “multilingüismo adverso" (Gramling, 2016, p. 47) que permite al régimen mantener su estatus. 
Finalmente, nos sentiremos preparados para abordar la cuestión del intérprete -Dolmetscher - en el universo concentracionario, que se manifiesta como una figura vital en un espacio de estas características; se trata, además, de una posición reglamentada y necesitada por el régimen opresor en cada KZ. En este sentido, partiremos de las investigaciones pioneras en este campo realizadas por las investigadoras Tryuk (2010, 2016a, 2016b), Wolf (2016a, 2016b) y Aschenberg (2016). Hasta ahora, algunas de las cuestiones sobre las que se ha indagado son las siguientes: el perfil personal y el proceso oficial de selección de los mediadores interlingüísticos; sus funciones determinadas; las consecuencias sociales y materiales de ejercer este oficio en el Lager; las técnicas concretas, el modo y el skopos del proceso interpretativo; y las posibles tendencias éticas que manifiestan los intérpretes.

Tras exponer sucintamente estas investigaciones para poder contextualizar la actividad interlingüística en el KZ, nos gustaría explorar una nueva perspectiva relacionada con la interpretación en el campo: trataremos de establecer las diferencias entre los actos oficiales de interpretación llevados a cabo por el Dolmetscher, y los actos espontáneos del deportado que, sin ejercer esta labor oficialmente, también siente la necesidad de convertirse, en una situación concreta, en un puente que permita la comunicación entre distintos individuos. Las posibilidades de estudio se abren en un abanico interminable, poco explorado, y que puede arrojar nueva luz sobre el proceder de los intérpretes en situación de máxima presión.

\section{Totalitarismo y poder absoluto}

En los campos de concentración el poder absoluto instaura un microcosmos social completamente aislado tras alambradas inexpugnables que, aunque pueda guardar similitudes con anteriores modelos históricos, manifiesta una evidente escisión respecto a la toda la trayectoria previa del poder. Sofsky ha definido el universo KZ como un sistema sui generis "donde se desarrollaba un tipo de poder que se diferenciaba considerablemente de los tipos corrientes de poder y dominación” (2016, p. 27). Hannah Arendt, por su parte, ha definido el Lager como "la verdadera institución central del poder organizador totalitario" (2006, p. 590). Si deseamos comprender la estructura social que se origina en estos espacios, por tanto, parece ilustrador antes presentar sucintamente algunas consideraciones básicas sobre el estado totalitario que se materializan y reflejan en las formas sociales surgidas en los campos.

En primer lugar, los dos teóricos coinciden en la importancia de la organización para estos sistemas: "el poder absoluto es el poder organizado" (Sofsky, 2016, p. 36); el poder "descansa exclusivamente en la fuerza lograda a través de la organización" (Arendt, 2006, p. 565). En este sentido, los testimonios de supervivientes del Lager evidencian la hiperregulación y la extrema categorización con la que el régimen opresor establece las jerarquías sociales que, asimiladas por los deportados, sirven para fomentar contrastes y estigmas entre los reclusos (Sofsky, 2016, p. 36).

En segundo lugar, el autor también señala la obediencia - esa "disposición general a hacer siempre lo que se exige" (p. 34), que se instala en el cerebro de los oprimidos - como un rasgo que favorece la dominación total, consolida y coordina las estructuras sociales de las sociedades totalitarias. La violencia es, evidentemente, la forma más pura que emplea el poder absoluto para someter al pueblo. Existen, sin embargo, también otras técnicas más sutiles utilizadas por el sistema — mediante el análisis, el control y, de nuevo, la organización de los procesos desarrollados en el Lager - , que generan una sensación de normalidad y, finalmente, "compone con los individuos amaestrados una máquina social que trabaja sin dificultades" (p. 34). En el campo, los supervivientes testimonian también esta mecanización sufrida diariamente: "nos convertimos en autómatas, 
obedeciendo las órdenes e intentando no pensar, para sobrevivir algunas horas más” (Venezia, 2010, p. 77). Este autor también relaciona la sensación de normalidad con el automatismo del prisionero: "Te acostumbrabas a todo. ... Al cabo de un rato ya no sentías nada. Habías entrado en la rueda que giraba" (p. 12).

A partir de estas líneas fácilmente se puede discernir un tercer rasgo caracterizador del poder absoluto, que Arendt ha puesto de manifiesto: la despersonalización y la necesidad de aniquilar cualquier indicio de espontaneidad como expresión de la naturaleza humana. El objetivo es controlar toda pluralidad y diferenciación personal para lograr erradicar cualquier individualidad de los sujetos, de manera que todos ellos resultan, finalmente, una masa intercambiable y superflua (2006, pp. 589-590). El superviviente de Auschwitz Paul Steinberg lo ha manifestado de forma explícita: "Todos los seres humanos que me rodean son intercambiables" (2004, p. 111). El sistema concentracionario es una máquina de despersonalización tan perfecta que, poco después de llegar, tras el ritual de ingreso, los deportados ya sienten los efectos de la deshumanización: "En algunos segundos, habíamos cesado de ser hombres" (Wiesel, 2013, p. 47).

De hecho, Arendt considera que el campo de concentración es el único espacio donde se puede llevar a cabo este experimento realmente, ya que es necesario mantener a los individuos absolutamente incomunicados del mundo exterior. En cuarto lugar, por tanto, constituye el aislamiento de la realidad exterior una característica vital del sistema totalitario, y considera la autora que es así como es posible explicar "la irrealidad peculiar [...] que caracteriza todos los relatos sobre los campos de concentración y que constituye una de las principales dificultades para la verdadera comprensión de la dominación totalitaria, que permanece o desaparece al mismo tiempo que la existencia de estos campos de concentración y exterminio" (2006, p. 590). Los propios supervivientes parecen dudar de la realidad a la que se enfrentan en su cautiverio: "Paradoja absoluta, hablar de realidad en relación con aquel universo" (Steinberg, 2004, p. 98).

Igualmente, Todorov ha puesto de manifiesto cómo el estado totalitario necesita controlar todas las esferas de la vida social del pueblo para lograr la sumisión completa. Al ser el único detentor incondicional de los fines últimos de la vida pública, el sistema logra que los individuos se guíen por una mentalidad instrumental que, de nuevo, al convertirlos en máquinas, da la impresión de eximirles de sus responsabilidades y difuminar las consecuencias de sus actos (2010, pp. 155-156). El hecho es que el poder absoluto consigue implicar a toda la población, de manera que todos los ciudadanos son cómplices y, al mismo tiempo, víctimas y verdugos (p. 174). El sistema de autogestión por parte de los reclusos que la organización nazi practica en el universo concentracionario constituye, una vez más, la máxima expresión de este principio totalitario, y sumerge a los reclusos en esa zona gris que enturbia la frontera entre persecutores y perseguidos.

Finalmente, podemos deducir que el estado totalitario no queda satisfecho con el establecimiento de un sistema basado en el terror injustificado y la violencia generalizada, sino que "transforma las estructuras universales de referencia del ser humano con el mundo" (Sofsky, 2016, p. 25) mediante la manipulación de las relaciones sociales del hombre y su percepción sobre sí mismo. Como los teóricos referidos en este apartado, consideramos que el campo de concentración representa el espacio en el que el poder absoluto logra poner en práctica sus principios de manera más eficaz. A la hora de emprender un estudio de cualquier índole sobre el universo KZ, es necesario primero reflexionar sobre el nivel de dominación que el totalitarismo impone sobre sus víctimas. En este contexto, todos los contactos sociales - y, por tanto, también los intercambios comunicativos - están sometidos a las más extremas fuerzas de coerción, y debemos esforzarnos en buscar ese reducido espacio de autonomía ulterior que existe incluso en las condiciones más adversas - la libertad espiritual de elegir la actitud 
con la que cada uno se enfrenta a su situación (Frank1,2001,p. 99) - para poder alcanzar conclusiones relevantes sobre la actividad de interpretación en este espacio totalitario.

\section{La expresión del totalitarismo en el Lager}

En un tempestuoso 1933, el pueblo alemán se entrega ciega y entusiasmadamente al nacionalsocialismo, de modo que el número de detenciones políticas asciende profusamente y las autoridades fundan, en Berlín y sus alrededores, los primeros y reducidos campos de concentración, a merced de la brutal S.A; las atrocidades allí cometidas eran actos de violencia individual, y el Lager todavía no se había convertido en el sistema de masas deshumanizador e industrial. Es a partir de 1936 cuando se comienza a crear la organización definitiva de los campos de concentración, bajo una dirección centralizada en Berlín, que los concibe como instalaciones estables y necesarias para el régimen (Kogon, 2005, pp. 66-67).

La organización sistemática del universo KZ lleva a las autoridades a decretar una clasificación: en el grado I se encuentran los más benignos, para prisioneros rehabilitables; el grado II representa un endurecimiento de las condiciones de vida y trabajo de los reclusos; y es prácticamente imposible sobrevivir a los campos del grado III, los molinos de los huesos, ideados para presos no rehabilitables que no se pretendía dejar salir con vida (Kogon, 2005, pp. 71-72). La clasificación no incluía los campos de exterminio, creados posteriormente. Ahora bien, aunque sea necesario considerar esta gradación para cualquier estudio, se debe remarcar que, verdaderamente, no se correspondía con la realidad de los campos: los factores que hacían que sus condiciones de vida pasaran de brutales a infrahumanas dependían de muchas variables.

Por ejemplo, mediante el análisis de la cronología es posible aproximarse todavía más al contexto real de los campos. Los supervivientes insisten en que la fase fundacional, hasta 1939, fue la peor de todas, la inseguridad era constante y se consolidó la miseria. Igualmente, el estallido de la guerra significó un agravamiento de las condiciones de vida: el abarrotamiento masivo generalizó las epidemias y la escasez de alimentos. Es en este momento cuando el Lager se convierte en una Torre de Babel cimentada en la confusión de lenguas (Levi, 1999, p. 35). A partir de 1942, se produjo un giro estratégico para servir al esfuerzo bélico; por primera vez, se comenzó a valorar los beneficios materiales que podía aportar la mano de obra; igualmente, a los nazis les importa también poder comunicarse de manera efectiva con los esclavos, de manera que la figura del intérprete concentracionario empieza a desarrollarse con más fuerza. Finalmente, durante los últimos años de la guerra, las condiciones de vida en el Lager volvieron a descender hasta niveles insufribles (Kogon, 2005, pp. 72-75).

Como Kuon (2016, pp. 144-145) advierte, es necesario crear un corpus comparativo de literatura concentracionaria para poder avanzar en el estudio; sin embargo, se deben evitar las comparaciones ad hoc y, previa a cualquier conclusión, es imprescindible la contextualización del autor y de las condiciones del Lager. Solamente así podemos explicar que un superviviente como Borowski - polaco no judío detenido por actividades subversivas - sobreviviera en Auschwitz, un campo de grado III: Borowski (2004, p. 36) llegó en abril de 1943, solo semanas después de que se dejara de gasear en masa a los reclusos arios; de esa manera, consiguió mantener siempre una posición privilegiada en el campo que le permitió salvar la vida.

El ejemplo del superviviente polaco ilustra acertadamente cómo, en el Lager, "la situación social estuvo determinada por el sistema de categorías, con el cual las S.S. clasificaban a los prisioneros; por el poder funcional [...]; por los contactos sociales y económicos con el personal" (Sofsky, 2016, p. 176). De hecho, considera el sociólogo alemán que la taxonomía de presos impuesta por la S.S. — que, manifestada externamente en la ropa 
del prisionero con triángulos y colores, ha sido definida por Goffman como un caso de "exhibición contaminadora" (1994,p. 36) - fue decisiva en la configuración de las clases sociales del KZ. El primer objetivo de la clasificación era distinguir hombre de infra-hombre - judíos, gitanos, eslavos - , pero también señalaba la nacionalidad así como el tipo de delito cometido - prisioneros políticos o delincuentes comunes - , y constituía el mecanismo de diferenciación que, asimilado por los reclusos, reproducía los estereotipos y organizaba una sociedad basada en la desigualdad absoluta (Sofsky, 2016, pp. 83-185).

Además, esta taxonomía era muy útil para la distribución de poder y funciones en el campo, cuya gestión y funcionamiento quedaba completamente en manos de los reclusos. La autoadministración designaba una élite funcional que controlaba el Lager; se trataba de una minoría, constituida principalmente por presos alemanes, encargada de las funciones que, por ser ligeras y permitirles sacar provecho personal, les confería una posición privilegiada en el campo. Mientras que la masa despersonalizada de prisioneros quedaba sumida en la miseria y destinada a los más duros trabajos, esta aristocracia colaboracionista - que se erigía como un órgano intermedio entre las S.S. y el deportado común - debía luchar por mantener su preeminencia. Es así como el régimen nacionalsocialista consigue establecer en el Lager uno de sus mayores logros: oscurecer la frontera que separa a víctima y verdugo.

Goffman ha señalado que el sistema de privilegios es inherente a todas las instituciones totales (1994, p. 60), y ha distinguido la "conversión" como uno de los métodos posibles de adaptación al ambiente. El interno converso asimila plenamente la visión que el sistema posee de él y se convierte en un pupilo perfecto; de ese modo, reproduce el comportamiento, los modales e incluso el lenguaje del personal, y desempeña con diligencia y crudeza la labor impuesta (p. 72). Sofsky ha acuñado el término de "servilismo mimético" (2016, p. 206) para referirse a esta tendencia, que lleva al colaborador a imitar la violencia de su señor con el fin de demostrar que es el hombre correcto para el trabajo, y así mantener su posición privilegiada.

En una sociedad - multicultural, racista y jerarquizada - en la que se debe luchar por la supervivencia diariamente, que promueve el uso de la violencia entre los propios reclusos y genera contrastes diferenciadores entre ellos, cualquier acto de solidaridad significa arriesgar la posición privilegiada y la propia vida; sin embargo, son muchos los ejemplos de prisioneros que se atrevieron a afrontar el peligro. En esta situación tan concreta, el comportamiento del intérprete - que es mucho más que un mero transmisor de mensajes: es un mediador social y cultural - merece ser estudiado. Sin embargo, parece necesario, tras haber analizado el entorno social que le rodea, explorar también el contexto lingüístico que surge en este espacio antes de poder realizar consideraciones acerca de la interpretación.

\section{El Lager como espacio multilingüe}

En 1946, David Rousset decidió referirse a él como L'univers concentracionaire, y otros autores también han deseado reiterar la otredad del archipiélago KZ, la inconmensurable distancia que lo separa del mundo exterior. La diferente naturaleza del Lager se manifiesta también en Chroniques d'ailleurs (1996), el título original de la obra de Paul Steinberg. Si lo consideramos, por tanto, como un mundo aparte, parece inevitable preguntarnos cuál es el lenguaje que corresponde a esta nueva realidad. La obra del judío alemán Klemperer, LTI: apuntes de un filólogo (2001), explora en profundidad cómo la lengua de Goethe se deforma en la sociedad alemana a lo largo del período de dominación nacionalsocialista para convertirse en lo que denomina Lengua del Tercer Imperio. Considera, de hecho, que el lenguaje es el instrumento más potente y eficaz de propaganda del 
movimiento, mucho más que las banderas, los discursos o las octavillas. Así, llega a afirmar que "el nazismo se introducía [...] en la carne y en la sangre de las masas a través de palabras aisladas, de expresiones, de formas sintácticas que imponía repitiéndolas millones de veces y que eran adoptadas de forma mecánica e inconsciente" (p. 31). Si el lenguaje adquiere un poder tan significativo en la sociedad externa alemana, debemos examinar en qué medida se desfigura el lenguaje en las sociedades concentracionarias y qué estructuras de poder representa, dado que el Lager significa la máxima expresión del sistema totalitario.

En efecto, el lenguaje y sus usos pragmáticos sufren una grave transformación en el campo de concentración. En otros trabajos hemos intentado perfilar cómo el sistema políglota concentracionario queda determinado por dos líneas de comunicación: una vertical y bidireccional, entre el opresor y los oprimidos; y una horizontal y multidireccional, que relaciona las lenguas de los deportados (Miñano-Mañero, 2016). Parece evidente que en el Lager existe una situación de diglosia que favorece el alemán frente a las demás lenguas de los reclusos. La lengua de poder que se emplea en el campo manifiesta rasgos argóticos - cargada de elementos deshumanizadores y agresivos hacia los prisioneros - y presenta una estructura gramatical simplificada, fragmentaria y repetitiva. Evidentemente, conocer la lengua del perpetrador era vital para la supervivencia del preso: por una parte, le permitía acceder a puestos de trabajo con mejores perspectivas y, así, ascender en la jerarquía social del campo; por otra, era absolutamente necesario para subsistir en el Lager ser capaz de descifrar las órdenes que se le exigían continuamente.

La primitiva lengua alemana que se utiliza en el campo se relaciona con una postura ambigua de las S.S.: es necesario que los deportados comprendan mínimamente para poder ejercer sus funciones, pero mantenerles en la ignorancia resulta fundamental para salvaguardar el sistema. Gramling (2016, pp. 46-47) considera que este "multilingüismo adverso", basado en la confusión de lenguas, es esencialmente lo que permite al régimen consolidar su opresión. La lengua se convierte en una arma de opresión, y las características del alemán empleado en el Lager sirven para conseguir esa dominación total que es el requisito fundamental inherente al sistema totalitario. Con una estructura brusca e iterativa, el lenguaje empleado por las S.S. es imitado por los serviles prisioneros-funcionarios de la zona gris y, a continuación, queda anidado también en las mentes de los reclusos comunes. El objetivo es el deseado: la violencia y despersonalización del lenguaje son asimiladas por toda la especie concentracionaria y se establece un régimen que permite la opresión absoluta.

Además de esta lengua alemana desfigurada - que cristaliza principalmente en la comunicación vertical del campo-, el sistema comunicativo del Lager cuenta con una lengua vehicular — "rooted in German, ... it manifests a rudimentary syntax and lexical elements from different languages" (Aschenberg, 2016, p. 69) - , un tipo de protolenguaje que permite la comunicación entre los deportados de distintas nacionalidades. Evidentemente, esta Lagerszpracha depende del contexto de cada campo. En el complejo de AuschwitzBirkenau, por ejemplo, existe una gran influencia del polaco, con neologismos e incluso declinaciones procedentes de esta lengua eslava que se funden con términos alemanes; en Mauthausen, en cambio, el gran flujo de españoles republicanos deportados concede importancia a su lengua. Según Gramling, "in the case of each camp language, the lexicon changed according to the staggered influx of dominant first languages in the respective camp. The sharp increase in Hungarians deported in 1944 shifted the lexical fundaments of Auschwitz camp language significantly away from Polish" (2012, p. 171). Tryuk (2010, p. 128) presenta evidencias de que esta lengua franca, creada principalmente para la comunicación de los presos, era en ocasiones empleada en el discurso de los propios SS.

Cuando se analizan las memorias de supervivientes, es posible apreciar que este idioma combinado del Lager manifiesta siempre el multilingüismo y el galimatías linguiístico de la sociedad concentracionaria: préstamos de 
una lengua se generalizan, siendo asimilados con rasgos fonéticos de los otros grupos nacionales; aparecen conversaciones híbridas, de escasa corrección gramatical, que incorporan léxico de diversas lenguas; y, por supuesto, la tendencia natural a la clarificación y comprensión mutua lleva a actos espontáneos de interpretación y, por ejemplo, a la enumeración sucesiva de un mismo término en distintos idiomas. Se acuñan neologismos para referirse a las nuevas realidades exclusivas del campo, se establecen nuevas acepciones y giros semánticos aplicados a la vida concentracionaria. La Lagerszpracha dispone también de un amplio repertorio retórico propio: las expresiones freaseológicas, las imágenes metafóricas y las creaciones sarcásticas afloran en lo que, tal vez, significa para los deportados que las acuñan una última forma de conservar algún resto de la libertad propia en un sistema en que incluso -o sobre todo- el lenguaje es impuesto.

Estudiar la figura del intérprete - que surge necesariamente en esta sociedad límite - parece conveniente para comprender el contexto sociolingüístico del Lager. Desde su posición, constituye el enlace entre las dos vías comunicativas del campo, puesto que posibilita el contacto entre el poder vertical y las lenguas del contrapoder. El intérprete-prisionero conoce la lengua alemana en profundidad y, al percibir la variable rudimentaria y degenerada que la S.S. utiliza en el campo, es susceptible de comprender en mayor medida que sus compañeros de cautiverio monolingües hasta qué punto la lengua es arma de opresión. Asimismo, por formar parte de la sociedad del contrapoder, conoce bien el repertorio lingüístico - así como sus connotaciones e implicaciones que entra en juego en la lengua franca del Lager. En este punto, nos sentimos preparados para indagar, a continuación, en algunas de las cuestiones que surgen al reflexionar sobre estos mediadores interculturales.

\section{Interpretación oficial y espontánea en el Lager}

La primera complicación que surge al emprender el estudio de la interpretación en campos de concentración es determinar quién desempeñaba esta función y cuál era el proceso de selección. A partir de sus investigaciones sobre el complejo Auschwitz-Birkenau, Tryuk ha encontrado evidencia de que algunos S.S. Volksdeutsche término de la LTI para referirse a las personas arias de habla y cultura alemana, sin importar su ciudadaníaejercían de intérprete en la Sección Política del campo y se encargaban del interrogatorio inicial (2010, p. 130). La mayor parte de los mediadores lingüísticos, sin embargo, se reclutaba entre los deportados. Los supervivientes Levi (1999, pp. 23-24) y Núñez (2005, p. 61) describen cómo, al llegar al campo, la S.S. invitaba a los prisioneros que hablaran alemán a presentarse; desde ese mismo momento, debían comenzar a traducir las órdenes del ritual de ingreso. En general, la selección del intérprete se producía de manera improvisada y precipitada; aunque Tryuk demuestra que, en Auschwitz, se realizó en una ocasión un examen de competencia lingüística en ruso y alemán a más de 100 internos para designar a los que aprobaran como intérpretes (2016a, p. 127).

La dificultad de establecer un perfil del Dolmetscher im Lager proviene de la naturaleza altamente heterogénea de este grupo. Las memorias muestran que las personas que lo componían no solo procedían de muchas nacionalidades, sino que exhibían distintos niveles de competencia en lenguas, dispares credenciales socioculturales y, sobre todo, diversas tendencias deontológicas en la ejecución de su función. Sus tareas en el campo también presentan variabilidad. Algunos de ellos eran empleados en las dependencias burocráticas del campo, donde podían encargarse de diversas labores administrativas o ejercían de secretarios de los oficiales de la Gestapo. Los intérpretes también eran vitales para establecer la comunicación en el ingreso de los recién llegados: por una parte, debían traducir el procedimiento ritual - abandono de pertenencias, selección, duchas y, solo para los más afortunados, desinfección - y, por otra, redactar los ficheros documentales con la información relativa a cada preso. Fuera de las oficinas, también eran necesitados para traducir los discursos de 
la S.S. y, en el Kommando de trabajo, las órdenes del Kapo. Wolf (2016a, pp. 104-105) señala que se trataba principalmente de una interpretación consecutiva sin toma de notas. No obstante, la expansión de las lenguas obligaba, en ocasiones, a una mediación indirecta a través de una tercera lengua, enlazando de ese modo la práctica de dos intérpretes y ralentizando el discurso meta. Con menor frecuencia, existe también evidencia de casos de interpretación susurrada.

Evidentemente, el ejercicio de estas responsabilidades - muchas de ellas a cubierto- implicaba una representativa mejora de las condiciones vitales del prisionero. Por ello, adquirir un puesto como prisionerofuncionario en la administración del campo significaba ascender en la rigurosa jerarquía social y potenciar las posibilidades de supervivencia. No obstante, Tryuk (2010, p. 130) revela que, en Auschwitz-Birkenau, los intérpretes de Kapos debían además realizar el trabajo regular de todos los presos y no se veían favorecidos materialmente por su labor de mediadores lingüísticos. Para ellos, señala la autora, son las ventajas de comunicación innatas a su naturaleza políglota el único beneficio. De cualquier manera, incluso los "pobres diablos" que trabajaban toda la jornada y además interpretaban para obtener tan solo una ración extra de sopa, "tendían a crearse una mentalidad típicamente corporativa, y a defender con energía su «puesto de trabajo» contra quienes, desde abajo, trataban de quitárselo" (Levi, 1989, p. 41).

Decididamente, ser seleccionado como Dolmetscher significaba ascender en la jerarquía del Lager, en mayor o menor medida. Por hablar ruso, la alemana comunista Buber-Neumann se incorpora inmediatamente al trabajo de intérprete y secretaria en un barracón de la empresa Siemens (2005, p. 325). Su categoría según los criterios étnicos de la S.S. y su conocimiento de lenguas le otorgan una posición privilegiada que le permite sobrevivir cinco años en Ravensbrück. Además de favorecer las perspectivas de supervivencia, los prisioneros eran conscientes del poder que la figura de intérprete confería. De esta cita se desprende el alto nivel de influencia al que podían aspirar los mediadores interlingüísticos en el campo:

\begin{abstract}
Homes ... més o menys coneixedors de la llengua alemanya, farien cada vegada més falta i ser intèrpret significava tenir influència. Els alemanys, SS o presos, que manaven a una banda i a l'altra de la filferrada, preferien sovint cedir els seus poders a l'intèrpret a la dificultat d'usar-los a través de la traducció. Era només qüestió d'introduirse poc a poc, de guanyar la seva confiança, d'obrar amb intel-ligència, de fer-se imprescindible i d'acabar amb el paper d'intermediari per a tenir-ne un de directe i executiu (Amat-Piniella, 1983, p. 19).
\end{abstract}

La interpretación, sin embargo, conlleva también riesgos derivados de la inevitable presencia física del mediador. Según Cronin (2006, p. 76-78), las consecuencias de la agencia oral y física del intérprete son ineludibles. Por una parte, el hecho de que posea un cuerpo situado en el tiempo y en el espacio significa que ese cuerpo, de manera voluntaria o inconscientemente, intentará dar expresión a su cosmovisión propia; por otra, la presencia física del intérprete le hace también especialmente vulnerable a las condiciones contextuales externas. Ahora bien, precisamente "his embodied agency which makes him uniquely susceptible to physical containment or destruction also accounts for his particular power in directly using languages to effect change at a crucial point (p. 81). Parece, por lo tanto, que la posición privilegiada e influyente del intérprete concentracionario es una arma de doble filo: mientras forzosamente arriesga su vida en cada escenario en que es requerido, es también capaz de influir decisivamente en las situaciones que se le presentan. Tryuk, examinando el comportamiento del Dolmetscher im Lager, considera que "this influence, fraught with danger, has no parallel in the history of translation" (2010, p. 143).

El hecho es que los principios deontológicos que rigen generalmente la actividad de la interpretación, tales como la objetividad, imparcialidad, neutralidad y precisión, parecen contradictorios cuando la mediación se lleva a cabo en una zona de conflicto. Malgorzata Tryuk sostiene que el papel de un intérprete es siempre activo y, 
además de aludir a cuestiones simplemente lingüísticas, conlleva también constantemente una reflexión y actuación para gestionar el carácter social así como intercultural del acto interpretativo (2010,p. 126). Estamos de acuerdo con la autora al afirmar que el Dolmetscher im Lager no podía de ninguna manera ser solamente un transmisor neutral de mensajes y, por lo tanto, que "in no other situation has an interpreter played such a deeply human role" (p. 143). Así, Tryuk defiende que en las situaciones extremas de violencia "the ethics of interpreting and translation loses its power and the generally accepted norms and standards are no longer applicable (2016b, p. 121). Desde nuestra postura, consideramos que es necesario ir todavía más allá en la aplicación de este principio: no es que los principios éticos tradicionales de la interpretación no sean vigentes en el Lager, sino que su aplicación, de hecho, resultaría en todos los casos antiética.

Para intentar ilustrar este principio, podemos partir del trabajo de Wolf (2016b, pp. 5-7), que investiga hasta qué punto la mediación linguística sirve para mantener y estructurar el orden de terror de la sociedad concentracionaria. La autora afirma que la interpretación conseguía - de manera muy limitada y sutil, pero también significativa - establecer una negociación de los términos del poder absoluto en el Lager. En su mediación interlingüística necesariamente sesgada, el Dolmetscher podía, esencialmente, personificar un instrumento más de opresión a disposición de la S.S. o, al contrario, posicionarse del lado del contrapoder.

La relación directamente proporcional entre colaboracionismo y supervivencia fomentada por el régimen lleva a muchos prisioneros-funcionarios al servilismo mimético que los convierte en herramientas opresivas del sistema. Así, Aschenberg (2016, p. 73) expone casos en los que los intérpretes adoptan el modo de hablar fragmentario y dañado de sus superiores, de ese modo contribuyendo a consolidar y expandir el lenguaje antiliberal del campo; también Wolf menciona una interpretación en staccato, presuntamente neutral y mecánica (2016a, p. 105) que, al deshumanizar la actividad mediadora, se revela también antiética. Un ejemplo de conversión lo presenta la catalana comunista Mercè Núñez (2005), deportada a Ravensbrück, al contar la historia de Hanka, "una jove polonesa molt agradable que parlava alemany i francès a la perfecció" (p. 61) que, poco después de comenzar su trabajo de intérprete "esdevingué una kapo més, que aniria dòcilment a cercar les xurriaques del comandant, li somriuria, donaria el menjar al seu gos i rebria com a preu dels seus serveis un bon plat de sopa de la cuina dels S.S. (p. 65)”. Núñez fue una de las reclusas que, por desconocimiento de la lengua de poder, debieron sufrir a causa de una mediadora colaboracionista que enfatizaba y defendía el orden totalitario del Lager. Aunque coincidieron en el mismo período en Ravensbrück, evidentemente la posición social de Núñez no es comparable a la de la veterana Buber-Neumann: la superviviente catalana, por su nacionalidad y su falta de competencia lingüística en alemán, nunca consiguió una situación privilegiada como la de BuberNeumann en la jerarquía social del campo. Los criterios raciales y lingüísticos, por tanto, predeterminaban las perspectivas del deportado en el universo concentracionario.

Ahora bien, Wolf (2016a, p. 108) afirma que, incluso este contexto extremo de corrupción, el skopos principal de la interpretación era el altruismo, la ayuda mutua y la solidaridad. Cuando Buber-Neumann trabaja como intérprete en la oficina de la vigilante S.S., no duda en cambiar las respuestas de las interrogadas rusas paras favorecer sus situaciones. (2005, p. 339). El ejemplo de la alemana, de este modo, simboliza al recluso que emplea su posición privilegiada para mejorar las condiciones de los demás. Igualmente, la intérprete francesa en una fábrica de Ravensbrück explicita su agencia oral y su posicionamiento al comenzar sus discursos con «Aquest banyut em fa dir...» (Núñez, 2005, p. 72). En definitiva, es evidente que las actuaciones concretas del intérprete sirven para negociar las condiciones de poder del Lager, para consolidar o subvertir el régimen. 
Finalmente, es necesario distinguir a estos intérpretes-funcionarios oficiales del Lager frente a todos los demás prisioneros multilingües que también realizan actos de mediación en situaciones concretas y de forma espontánea, aunque no ostentan el cargo de Dolmetscher. Defendemos que estos casos demuestran una tendencia humana natural orientada a la clarificación y la comunicación, así como un skopos verdaderamente solidario por parte del mediador ad-hoc que, de manera inconsciente, comprende instantáneamente la relevancia de las lenguas en el contexto extremo del Lager. Aunque nunca llegó a trabajar de intérprete en el campo, el políglota Paul Steinberg (2004, p. 45-46) deduce, ante su inminente deportación a Alemania junto a reclusos franceses monolingües, la importancia de su perfil: "De repente, me vi convertido en un elemento fundamental del grupo, pues era el único que hablaba fluidamente alemán. Iba a ser su intérprete, su guía, su consejero”.

Efectivamente, cuando Steinberg llega, comienza a traducir de manera instintiva a sus conocidos los discursos de los oficiales (p. 78). Conscientemente, el autor decide omitir parte del contenido agresivo que juzga solamente desmotivador para sus amigos: "No traduje a mis compañeros la frase fatídica con que terminaban la mayoría de alocuciones oficiales: .... «Von hier geht es nur durch den Schornstein raus» (De aquí sólo se sale por la chimenea)" (p. 81). Al descartar, guiado por su skopos solidario, parte del contenido del discurso alemán de forma deliberada, Steinberg está, sin embargo, manipulando la percepción de la realidad que experimentarán, de manera más suavizada, sus compañeros de reclusión franceses. Parece que cada acto de interpretación, en el contexto concentracionario, conlleva una manifestación de poder considerable. Como el mismo Steinberg comprende, su figura multicultural le confiere, automáticamente, un papel influyente que excede en gran medida la simple mediación lingüística.

\section{Conclusión}

En este contexto, el estudio de la figura del Dolmetscher parece especialmente relevante. Al ser el enlace que permite la comunicación entre las capas sociales del Lager, su posición privilegiada como mediador lingüístico, cultural e interpersonal le otorga una autoridad especial en el campo. De hecho, a partir de su actividad los intérpretes podían influir de manera significativa en el desarrollo de los acontecimientos cotidianos en estos espacios. En una situación de máxima opresión, algunos mediadores interlingüísticos se posicionan junto al poder, pero muchos otros, arriesgando sus propias vidas, intervienen para favorecer a los demás reclusos. Investigar de manera más concreta las técnicas y los métodos que sirven a estos intérpretes para ejercer ambas posturas resulta útil para comprender mejor el funcionamiento de la estructura social del universo concentracionario.

Igualmente, parece ilustrador diferenciar a los intérpretes reglamentados de todos aquellos mediadores ad-hoc situacionales que actúan de manera espontánea en un momento determinado, sin ser su trabajo la interpretación y $\sin$ - aparentemente - obtener nada a cambio. De este trabajo se desprende que la reflexión sobre el Dolmetscher concentracionario, en todas sus facetas y posibilidades, resulta conveniente para avanzar en la investigación sobre la interpretación en general y sobre la mediación interlingüística en realidades extremas en particular. 


\section{About the author}

Laura Miñano Mañero es graduada en Traducción y Mediación Interlingüística (Inglés-Alemán) por la Universitat de València, donde también ha realizado un Máster en Traducción Creativa y Humanística. Actualmente se ha incorporado con una beca FPU al departamento de Teoria dels Llenguatges i Ciències de la Comunicació de la misma universidad para realizar su proyecto doctoral, titulado: Las lenguas en los campos de concentración: contacto, acción y vivencia.

\section{Referencias bibliográficas}

Amat-Piniella, J. (1984) [1963]. K.L. Reich: els catalans als camps d'extermini de Hitler. Barcelona: Edicions 62, S.A.

Arendt, H. (2006) [1951]. Los orígenes del Totalitarismo. Madrid: Alianza.

Aschenberg, H. (2016). Linguistic Terror in Nazi Concentration camps: Lucien and Gilbert, Portraits of Two "Interpreters". En Wolf. M. (Ed.), Interpreting in Nazi Concentration Camps (pp. 63-78). London: Bloomsbury Academic.

Borowski, T. (2004). Nuestro hogar es Auschwitz. Barcelona: Alba Editorial, S.L.

Buber-Neumann, M. (2005) [1949]. Prisionera de Stalin y de Hitler. Barcelona: Galaxia Gutenberg.

Cronin, M. (2006). Translation and Identity. New York: Routledge.

Frankl, V. (2001) [1946]. El hombre en busca de sentido. Barcelona: Herder.

Goffman, E. (1994) [1961]. Internados: Ensayos sobre la situación social de los enfermos mentales. Buenos Aires: Amorrortu Editores.

Gramling, D. (2012). An Other unspeakability: Levi and Lagerszpracha. New German Critique, 117, 39(3), $165-187$.

Gramling, D. (2016). Translanguagers and the Concentrationary Universe. En Wolf, M.(Ed.), Interpreting in Nazi concentration camps (pp. 43-55). London: Bloomsbury Academic.

Klemperer, V. (2001) [1947]. LTI: Apuntes de un filólogo. Barcelona: Editorial Minúscula.

Kogon, E. (2005) [1946]. El Estado de la SS: el sistema de los campos de concentración alemanes. Barcelona: Alba Editorial.

Kuon, P. (2016). "L'écrit reste. L'écrit est une trace, tandis que les paroles s'envolent": On the Hermeneutics of Holocaust Survivor Memoirs. En Wolf, M. (Ed.), Interpreting in Nazi concentration camps (pp. 149-160). London: Bloomsbury Academic.

Levi, P. (1989) [1986]. Los hundidos y los salvados. Barcelona: Muchnik Editores, S.A.

Levi, P. (1999) [1947]. Si esto es un hombre. Barcelona: Muchnik Editores, S.A.

Miñano-Mañero, L. (2016). Las lenguas en los campos de concentración: acción, contacto y vivencia. Lynx: Panorámica de Estudios Lingüísticos, 15, 135-154.

Núñez, M. (2005) [1980]. El carretó dels gossos. Barcelona: Edicions 62.

Prenninger, A. (2016). The Camp Society: Approaches to Social Structure and Ordinary Life in Nazi Concentration Camps. En Wolf, M. (Ed.), Interpreting in Nazi concentration camps (pp. 25-40). London: Bloomsbury Academic.

Rousset, D. (2010) [1946]. L'univers concentracionaire. Paris: Pluriel.

Sánchez Zapatero, J. (2010). Escribir el horror: Literatura y campos de concentración. Barcelona: Editorial Montesinos.

Sofsky, W. (2016) [1997]. La organización del terror: los campos de concentración. Buenos Aires: Prometeo Libros.

Steinberg, P. (2004) [1996]. Crónicas del mundo oscuro. Barcelona: Círculo de Lectores.

Todorov, T. (2010). Le siècle des totalitarismes. Paris: Éditions Robert Laffont.

Tryuk, M. (2010). Interpreting in Nazi concentration camps during World War II, Interpreting, 12(2), $125-145$. 
Tryuk, M. (2016a). Interpreting and translating in Nazi concentration camps during World War II. Linguistica Antverpiensia, New Series: Themes in Translation Studies, 15, 121-141.

Tryuk, M. (2016b). Interpreters in the Concentration Camp of Majdanek (1941-1944). En Wolf, M. (Ed.), Interpreting in Nazi concentration camps (pp. 115-133). London: Bloomsbury Academic.

Venezia, S. (2010) [2007]. Sonderkommando: el testimonio de un judío obligado a trabajar en las cámaras de gas. Barcelona: RBA Libros, S.A.

Wiesel, E. (2013) [1958]. Trilogía de la noche. Barcelona: Austral.

Wolf, M. (2016a). Someone whispered the translation in 100 languages, like a Babel...": Interpreting in the Mauthausen Concentration Camp. En Wolf, M. (Ed.), Interpreting in Nazi concentration camps (pp. 95-113). London: Bloomsbury Academic.

Wolf, M. (2016b). Introduction: Interpreting in Nazi Concentration Camps - Challenging the "Order of terror"? En Wolf, M. (Ed.), Interpreting in Nazi concentration camps (pp. 1-21). London: Bloomsbury Academic. 